MEMÓRIA

\title{
O Fundo Nacional de Desenvolvimento Científico e Tecnológico - FNDCT e a Financiadora de Estudos e Projetos - FINEP*
}

\begin{abstract}
Amílcar Figueira Ferrari
Assessor para D esenvolvimento Institucional da Fundação C esgranrio. Ele sucedeu a José Pelúcio Ferreira como gestor do Fundo de D esenvolvimento Técnico Científico (FU N TEC) do então Banco $N$ acional do D esenvolvimento Econômico (BN D E) (1970-1975), foi D iretor do Conselho $\mathrm{N}$ acional de D esenvolvimento Científico eTecnológico (CN Pq) quando Pelúcio era o Vice-Presidente (19751980), foi Subsecretário de Estado de Ciência e Tecnologia do Rio de Janeiro quando Pelúcio era o titular da pasta (1987-1991).
\end{abstract}

\section{O Fundo}

M esmo considerando as ações sendo desenvolvidas pelo Conselho $\mathrm{N}$ acional de Pesquisas- CN Pq, cujo titular, à época, do ponto devistaformal, respondia diretamente ao Presidente da República, pela Coordenação de Aperfeiçoamento do Pessoal de N ível Superior - CAPES do M inistério da Educação e Cultura - MEC e pelo Fundo de Desenvolvimento T écnicoCientífico - FUNTEC, do então Banco N acional do Desenvolvimento Econômico - BNDE, vinculado ao Ministério do Planejamento e Coordenação Geral - MPCG e por outras agências federais, ou talvez até pelo contrário, como conseqüência dessasações, percebia-se, no final da década de 1960, a carência de apoio a

"um sistema de pesquisas científicas e tecnológicas que refletisse as necessi dades efeti vas e potenciais da economia brasilei ra e que passasse a

\footnotetext{
Este texto é, com poucos ajustes, uma transcrição do capítulo homônimo de "José Pelúcio Ferreira e a Pós-Graduação no Brasil"/Amílcar Figueira Ferrari - Brasília - Paralelo 15, Coordenação de Aperfeiçoamento de Pessoal de Nível Superior, 2001.
} 
conduzir o processo de expansão de seu aparelho produtivo sincronizado com a revolução científica etecnológica" ${ }^{1}$, que se achava em curso.

Para responder a essa percepção, foi criado em 31/07/1969, pelo D ecretolei $\mathrm{n}$-. 719, o Fundo $\mathrm{N}$ acional de D esenvolvimento Científico eTecnológico FNDCT,

"com a finalidadede dar apoi o financei ro aosprogramase projetosprioritários de desenvol vi mento ci entífico etecnológico, notadamentepara a implantação do Plano Básico deD esenvolvimento CientíficoTecnológico - PBDCT".

0 mesmo D ecreto-lei previu que a aplicação dos recursos do fundo obedeceria

"a diretrizes, planosenormasexpedidaspor um Consel ho D iretor, constituído pelo M inistro do Planejamento eC oordenação $\mathrm{G}$ eral, como Presidente, pelo Presidente do CNPq, como Vice-Presidente, pelo Presidente do BNDE e por representantes do M EC, do M inistério das M inaseEnergia, do M inistério da I ndústria e do Comércio, e de outros setores, públicos e privados, ligados ao desenvolvimento científico e tecnológi co nacional , conforme se dispuser em D ecreto",

o que não chegou a ocorrer. É provável ter sido antevista a dificuldade prática de reunir as autoridades arroladas e, até mesmo, a possibilidade de disputas por financiamentos entre os órgãos governamentais representados.

O D ecreto previa ainda que o fundo seria "dotado de uma SecretariaExecutiva cuja organização e funcionamento" seriam "estabelecidos em Regulamento", o que só viria a ser possível quase um ano depois, por D ecreto que atribuiu à Financiadora de Estudos e Projetos - FIN EP essa função.

Exatamente um mês depois da criação do FN D CT, o G overno sofre brusca interrupção. Em face da gravidade do estado de saúde do $M$ arechal Arthur da C osta eSilva, a junta militar constituída pelos M inistros da M arinha, do Exército e da Aeronáutica, declarando vagos os cargos de Presidente e de Vice-Presidente da R epública, assume provisoriamente o poder.

D oismeses depois, a 30 de outubro, toma posse como novo Presidente o General Emílio G arrastazu M édici, quenomeia oão Paulo dos Reis Velloso,

Relatório de Atividades - FINEP - 1965 - Junho de 1973. 
anteriormenteSecretário-Geral do M inistério do Planejamento eC oordenação Geral - M PCG, para titular desta pasta.

Velloso convida Pelúcio que, àquela altura, já havia transformado as idéias e as operações do FU N TEC em sucesso plenamente reconhecido, para atuar como secretário executivo do FNDCT. Para tal, cedido pelo BNDE, foi nomeado Secretário-G eral Adjunto do M PCG e Coordenador do N úcleo IV - Indústria, Ciência eTecnologia, M arcos Pereira Vianna, que viria a ser mais tardePresidente do BN D E, já havia sido nomeado Secretário-G eral.

O local de trabalho de Pelúcio deslocou-se da av. Rio Branco, esquina com V isconde de Inhaúma, on de estava instalado o BN DE, para o 6․andar do Edifício do M inistério da Fazenda, na av. Presidente Antônio C arlos, no Rio de aneiro.

O espaço físico e as instalações eram acanhados. A equipe disponível, muito pequena, era pouco familiarizada com os assuntos de C iência eTecnologia. Para tratar da análise de projetos propriamente dita, Pelúcio recorria ao aconsel hamento externo, que foi coordenado por Acher M osse, doutor em engenharia, cedido informalmente pela Coordenação dos Programas de Pós G raduação em Engenharia- CO PPE da UniversidadeFederal do Rio deJaneiro, onde ele acabara de organizar, a pedido de Alberto Luiz Coimbra, criador e diretor daquela coordenação, a CO PPETEC como unidade promotora de contratostecnológicos externos, prática comum nos países desenvolvidos, porém novidade no Brasil, pela qual foi o primeiro responsável. Acher conseguiu que C ésar G onçal ves N eto, então mestrando deEngenharia de Produção, o assistisse, principalmentena adequação formal dosprojetos em análise.

O s projetosaprovados parafinanciamento nessa fase dearrumação inicial de casa, em que o FU N TEC continuava em plena operação, não foram muitos: em 1970, apenas sete, de que foram beneficiários a Comissão $\mathrm{N}$ acional de Energia N uclear - CN EN , o M inistério da M arinha, a CAPES, a Academia Brasileira de Ciências - ABC, em dois casos, o Centro T écnico Aeroespacial CTA do M inistério da Aeronáutica. Além de, único caso do Setor de D esenvolvimento Científico e Formação de Recursos H umanos, a Pontifícia UniversidadeC atólica do Rio de Janeiro - PUC/RJ .

$\mathrm{N}$ a ausência de mecanismos institucionalizados, optou-se por reunir projetos analisados com parecer favorável em Exposições de M otivos, que 0 
M inistro de Estado levava à consideração do Presidente da República, cuja aprovação era necessária para conceder os financiamentos nela constantes. Este procedimento foi mantido por vários anos, pelo menos durantetodo o período em que Pelúcio esteve à frente do FN D CT ${ }^{2}$.

Pelúcio pôde obter o concurso de J osé Walter Bautista Vidal, que havia completado sua gestão à frente da Secretaria de Estado deC iência eTecnologia da Bahia, no G overno Luiz Vianna Filho e, al guns meses depois, o deE duardo Rappel, que havia decidido se exonerar da direção do Centro de Pesquisas e D esenvolvimento, CEPED, daquele mesmo Estado, por dificuldades encontradas no novo G overno. A colaboração deles concentrou-se sobretudo nos assuntos de planejamento.

\section{A empresa}

"Embora dispusesse o empresariado nacional de inúmeras fontes financiadores, quer oficiais quer particulares, ressentia-se o mercado de um instrumento de apoio à fase inicial de qualquer empreendimento: o projeto, plano ou programa.

$\mathrm{N}$ ão é preciso dizer que essa ausência implicava em resultados em grande partedesvantajosospara o setor empresarial, por um lado e, por outro, facilitava a dispersão de recursosem aplicaçõesnão passívei sdesucesso ou sem repercussão econômica ou social. Visando a suprir tal lacuna, idealizou o G overno Federal a criação de uma fonte financeira que, através de sua atuação, desenvolvesse as possibilidades então exi stentes no setor." 3

É bastante plausível supor que Roberto de O liveira Campos, M inistro Extraordinário para o Planejamento e Coordenação Econômica, tivesse bem presentea importânciafundamental do uso adequado do conceito deprojeto que ele, uma década atrás, havia introduzido no BNDE. Assim é que, o FINEP Fundo deFinanciamento deEstudos deProjetos eProgramas destinado a prover recursos para o financiamento da elaboração de projetos e programas de desenvolvimento econômico foi criado pelo $D$ ecreto $n=55.820$ de 8 demarço de

\footnotetext{
Desempenho Operacional - FINEP/FNDCT (1970-1978); Programação Financeira (1979-1981) - Biblioteca da FINEP.

3 Relatório de Atividades - FINEP - 1965 - Junho de 1973.
} 
1965. 0 Fundo tinhanatureza contábil, constituindo uma contagráficano BN DE e coordenado por uma Junta, cujo Secretário Executivo dirigia seu Escritório dentro do $\mathrm{G}$ abinete do M inistro.

"A inexistência de personalidade jurídica, exigindo a atuação do fundo exclusivamente através de Agentes Financeiros, tornava suas operações morosas e difícés. I Ito se agravou mais ainda quando, através do $D$ ecreto no. 56.835 de 3 de setembro de 1965, que constituiu 0 FUN AGRI, foi o FUND 0 absorvido e transformado em uma subconta do Fundo $G$ eral para Agricultura el ndústria, sob a getão do B anco Central do Brasil.Em decorrência de uma série de di pl omas legais como $0 \mathrm{D}$ ecretolei $n .200$ (art.91), de 25/02/67, D ecreto-lei $\mathrm{n} \cong .298$, de 28/02/67 e Decreto $n-61.056$ de $24 / 07 / 67$, foi constituída a empresa pública FIN AN CIAD ORA DE EST UDOSDE PROJETOSS/A - FINEP, que absorveu asfunções do FU N D O , poden do atuar com mais sesembaraço e eficiência no setor específico de suasatribuições.

... atuou a Empresa no mercado de consultoria de projetos, tendo em mira sempre prestigiar a engenharia nacional, influenciando, através de sua di reção, a criação de nor mas legais de proteção e etímul o a esse campo de atividade, ao mesmo tempo em que procurava disciplinar os custos e qualidade dos serviços.

... dedicou sua atuação básica ao financiamento, diretamente ou através de seus agentes, de programas, projetos ou estudos considerados prioritários, seja no âmbito federal, estadual, municipal ou privado.

Entretanto, esta faixa de atuação da Empresa era considerada acanhada para as potencialidades que sua estrutura permitia explorar. ${ }^{4 "}$

A 15 demarço de 1971, mantendo sua posição deSecretário G eral Adjunto do M PCG , Pelúcio foi nomeado PresidentedaFIN EP, em substituição aFrancisco $M$ anoel de M ello Franco, primeiro titular da empresa, a cuja frente esteve desde sua constituição em 1967 eque assumia funções elevadas de assessoramento no Governo do Estado da Guanabara. Para Vice-Presidente, em substituição a Joaquim Francisco de $C$ arvalho, foi nomeado a 31 do mesmo mês Alexandre $H$ enriques Leal Filho, que havia trabalhado com Pelúcio no BN DE. 
Pelúcio levou também para a FIN EP, já no começo de 1972, Clélia da Silveira Muniz, a quem conhecia bem do BNDE, onde, embora não pertencente aos quadros do Banco, trabalhava no lá instalado escritório da CO PERBO - Companhia Pernambucana de Borracha Sintética.

Alexandre como Vice-Presidente e C lélia de início assessora, depois Chefe do $D$ epartamento de Administração e, a partir da instalação da $D$ iretoria colegiada em 1975, como C hefe de G abinete, acompanharam Pelúcio até o final do Governo G eisel, em 15 de março de 1979.

Três meses depois de Pelúcio assumir sua Presidência, pelo D ecreto $n$ ㅇ․ 68.748, de 15 de junho de 1971, que também alterou o nome da empresa de Financiadora deEstudos de Projetos para Financiadora de Estudos eProjetos, a FIN EP passou a exercer asfunções de Secretaria Executiva do FN DCT.

"A idéa básica não era simplesmente a de etender ainda mais a ação financiadora da FIN EP, massim a deconferir a esta ação uma racionalidade funcional maisampla eeficaz, pelas razõesabaixo enumeradas.

1․ U m determinado projeto poderia receber o suporte financerro da FIN EP em toda equalquer de suasfases, ou seja: pesquisa básica - pesquisa aplicada - desenvolvimento experimental - estudo da viabilidade econômica - engenharia final.

2‥ A continuidade da seqüência "pesquisa - empreendimento" estaria assegurada. 0 pesquisador teria um horizonte maisamplo para os resultados de sua pesquisa e o empresário investidor depositaria maior confiança nos produtosda pesquisa.

30. A ligação "pesquisa - empreendimento" seria mais reforçada com a introdução deum outro elo na cadeia: a consultoria. À FIN EP eàsfirmas de consultoria caberia o papel deméo difusor eamplificador detecnologi a." 5

$\mathrm{N}$ a formação de sua equipe, Pelúcio procurou recrutar técnicos de duas camadas, que ele via como complementares. U ma delas, integrada por pessoas mais jovens, porém já tendo feito cursos de Pós-G raduação ou que tivessem interesseem fazêlosno futuro; a outra, deprofissionaisque, além demuito bem formados tecnicamente, tivessem experiência profissional desenvolvida em ambientedequalidade. 
N esta última, Pelúcio, tendo acompanhado no BN DE os úteis aportes trazidos por $O$ ficiais da reserva do Exército, formados pelo I nstituto $\mathrm{M}$ ilitar de Engenharia, recorreu a eles. V ieram inicialmente os Coronéis Romeu D iniz de Carvalho eLeonel M artins N ey daSilva. D epois, ao longo do tempo, os G enerais Renato Paiva Rio; Aristóbulo Codevilla Rocha; os Coronéis Ary Barbosa Kahl, H élio Pinto G uedese Carlos Antônio Lopes Pereira.

$\mathrm{N}$ a primeira, W ilson N ogueira Rodriguez, engenheiro, mestrepor Stanford, que tinha trabalhado com Pelúcio no BN DE; Bruno Luiz Ribeiro da Silveira, advogado, com Pós-Graduação em H arvard; Fábio Celso de M acedo Soares Guimarães, engenheiro; Frederico Barros Barreto, engenheiro.Logo após, Luiz Fernando Sal gado C andiota, engenheiro, mestrepor H ouston, do Centro T écnico Científico - CTC da PU C/RJ; Fábio Stefano Erber, economista, também do BN D E; Paulo Roberto Krahe, doutor em engenharia metalúrgica, que regressava da França; além do Vice-PresidenteA lexandre, engenheiro, mestrepor Stanford. Paulo G ustavo M igon, economista, Joaquim Loureiro, advogado, evários outros, quejá estavam naFIN EP desdeaadministração anterior, continuaram naEmpresa.

Eram todos, os acima citados, e outros de mesmo gabarito, que foram sendo recrutados, assessores do Presidente, que a eles entregava tarefas específicas segundo suas habilitações, cujo conhecimento Pelúcio permanentemente aprofundava. A Empresa funcionou assim nos seus primeiros tempos. D epois, com o volume de trabal ho crescendo, foram sendo organizados grupos setoriais como deAgricultura eA bastecimento, Administração eG erência, Comunicações, D esenvolvimento U rbano eR Regional, D esenvolvimento Científico eTecnológico, Energia, Indústria, Saúde eSaneamento eTransportes, cada um com sua chefia.

Em casos especiais, a FIN EP contratava consultores externos. Walter $M$ annheimer, doutor em engenharia metalúrgica, cedido pela CO PPE, foi consultor de tempo integral por quase um ano.

J osél srael Vargas relatou-meque, já de regresso à U niversidadeFederal de M inas G erais, depois dos seisanos em que estivera na U niversidade de Grenoble, França, como professor-visitante, recebeu um telefonema de Pelúcio propondo uma reunião. Acertaram o horário para o dia em que Vargas teria de vir ao Rio por outra razão.

Antes de ir à FIN EP, Vargas atendeu ao outro compromisso, que era com Walter M oreira Salles. Lá, foi convidado para ser assessor direto, incumbido de, 
tendo em vista os avançosque se verificavam no exterior, examinar eacompanhar os fatores tecnológicos pertinentes que pudessem aumentar a produtividade nas empresas do G rupo M oreira Salles. As condições de trabalho oferecidas eram assaz vantajosas, mesmo assim Vargas ficou depensar, para responder em breve.

Conheciam-se apenas de nome e de referências. Só na FIN EP vieram a se ver frente a frente. Pelúcio discorreu sobre as idéias que ele tinha em mente epediu a colaboração de Vargas, queaquiesceu, talvez por polidez, em assessorar a empresa no que ele pudesse, mas com a condição de não ser remunerado. Foi-Ihe explicado que a legislação não permitia isso. Trocaram idéias gerais para se comunicarem no futuro e, já de pé, começavam a se despedir, quando ocorreu a Vargas perguntar quem tinha sugerido o nome dele. Ao saber ter sido Celso Furtado, Vargas voltou a se sentar e a conversa continuou em termos mais concretos.

Para assombro eal guma decepção defamiliares eamigosmuito próximos, Vargas aceitou ser consultor da FINEP, residente em Belo H orizonte. Seu primeiro trabalho foi a condução deum estudo sobreosinsumos, especialmente sobre os não ferrosos, constantes da pauta de importações, indicando os casos em que, promovidos os necessários desenvolvimentos tecnológicos, que seriam explicitados, pudessem vir a ser produzidos no País. 0 estudo foi levado a termo e seus resultados foram de utilidadepara orientar as prioridades deal guns programas daFIN EP. A associação entreos dois, iniciada ali, ora maispróxima, ora mais distante, conforme as circunstâncias detrabal ho decada um, nunca se desfez e levou à amizade que até hoje perdura.

A FIN EP estava instalada no Edifício Aliança da Bahia, na rua Anfilófio deCarvalho, muito próxima ao Edifício do M inistério da Fazenda, ondePelúcio mantinha seu gabinete de Secretário G eral Adjunto do M PCG . 0 espaço era adequado para as finalidades anteriores da Empresa, mas não compatível com astarefas exigidas pela Secretaria Executiva do FN D CT. Cerca de um ano depois, ainda no primeiro semestre de 1972, a FIN EP mudou-se para a av. Presidente Vargas, esquina com rua M iguel C outo, ondePelúcio se sentia bem, porque era perto do BNDE. 0 alívio foi grande mas, com o crescimento da Empresa, durou pouco, apenas o primeiro ano do contrato de locação. Alexandre, conseguiu convencer um relutante Pelúcio, que se preocupava com as despesas decorrentes, a mudar aFIN EP, em 1973, para o Edifício do ClubedeEngenharia, 
na av. Rio Branco, esquina com rua Sete de Setembro, onde a Empresa permaneceu por cerca de duas décadas.

Reflexo do crescimento da Empresa é a evolução do seu quadro de servidores. De 30 empregados, no final de 1971, chegou, por incrementos bastante harmônicos, a 500, no final de 1978. Ao longo detodo o percurso, 0 equilíbrio entre o número de técnicos de nível superior e o número de funcionários deapoio administrativo, praticamentemeio a meio, foi mantido.

Em junho de 1972, foi celebrado entre o Banco Interamericano de D esenvolvimento - BID eaFIN EP contrato deempréstimo deU $\$ 10$ milhões. Pelúcio foi o grande artífice desse que veio a ser o primeiro empréstimo do BID na área de ciência e tecnologia. Fui testemunha, porque chamado a participar tanto aqui quanto em Washington, das dificuldades, que por vezes pareciam insuperáveis, nas negociações conduzidas, dada a inexperiência daquel eBanco no assunto. É inesquecível, numa das muitas missões que enviaram ao Brasil, a tentativa de um economista do BID de exigir uma correlação entre a construção do novo prédio do Instituto de $M$ atemática Pura e Aplicada IMPA e o crescimento do PIB per capita do Brasil. Foi o profundo conhecimento de Pelúcio da importância da ciência e tecnologia no desenvolvimento econômico e social e a sua tenacidade que levaram os entendimentos a um desfecho favorável. 0 empréstimo tornou-seum modelo para o BID , que o reproduziu depois com outros países do continente, e até para o Banco M undial, cuja primeira operação com ciência e tecnologia veio a se concretizar al guns anos mais tarde com a Espanha.

O Estatuto da FINEP, aprovado pelo Decreto no. 71.133 de 21 de setembro de 1972, atribuiu a um Consel ho D iretor de seismembros, composto pelo Presidente, o V ice-Presidentee representantes do Instituto dePlanejamento Econômico e Social - IPEA, do Banco Central, do BN DE e do Consel ho de D esenvolvimento Industrial - CD I, a deliberação sobre a orientação geral das atividades da empresa e a fixação de prioridades.

“Em 1975, a FINEP passou por profundas modificações iniciadas com a alteração dos seus estatutos, aprovados pel o D ecreto nํ. 75.472, de 12 de março de 1975, que instituiu uma D iretoria Executiva composta pelo Presidente, pelo Vice-Presidente e por quatro Diretores. Em decorrência, procedeu-se à distribuição de atribuições entre os $D$ iretores, efetivando-se na 
estrutura da FIN EP asnecessárias alteraçõesorganizacionais Taismudanças permitiram a adequação da Empresa às suas necessidades atuais e previstas para futuro próximo.

A criação da nova D iretoria foi induzida pelo próprio crescimento da Empresa, que tinha no seu Presidente eVice-Presidente a concentração de responsabilidade pelas deci sões, ficando, portanto, intensamente absorvidos com as operações de colaboração financei ra. D esse modo, os novos Estatutos consagram o princípio de direção colegiada e propiciam a cada Diretor administrar uma parcela das diversas atividades da Empresa, quer sejam de apoio quer operacionais, a par da contribuição ao planejamento do desenvolvimento da FINEP.

Tendo em vista a complexidadee o acel erado ritmo de desenvol vi mento de suas atividades, tornou-se indispensável que a empresa dispusesse de estrutura flexível capaz de promover adaptações sempre que se faça mi ster. Assim sendo, a nova estrutura básica foi fundamentada em programas, todos elesdecorrentes da necessidadeatual edascaracterísticas próprias da Empresa. Assim, por exemplo, no transcurso de 1975, a FIN EP procurou reforçar e ampliar suas características de banco de desenvolvimento científico e tecnológi co, apoiando efinanciando desdea pesquisa básica atéo processo de engenharia final.

D asdemaisalterações promovidas pelo novo instrumento vale destacar a capaci tação da FIN EP : a) na parti ci pação do capital social deempresas, como decolaboração financei ra; b) em assumir a responsabilidadedeelaborar, direta ou indi retamente, estudose projetoscons deradosprioritários, negociando com grupos ou entidades o aproveitamento dos resultados; c) na busca da efetiva implementação de resultados advindos de projetos e etudos já financiados, inclus veutilizando-sedascaracterísticas descritasnositensa eb anteriores." 6 Este Estatuto introduziu o Consel ho daFIN EP, com responsabilidades, embora mais detalhadas, não muito diferentes das do Conselho Diretor anterior, e composição muito parecida. A penas o representante do CDI foi substituído pelo representante do $\mathrm{M}$ inistério da Indústria e do Comércio.

Foram nomeadosD iretores, a partir dejunho, tendo ficado noscargosaté 
o fim da gestão de Pelúcio: Fábio C elso deM acedo Soares Guimarães, funcionário da casa, que no G overno Sarney viria a ser Presidente da Empresa, e W ilson N ogueira Rodriguez, quehavia trabalhado com Pelúcio no BN DE, emborativesse se afastado do Banco, fazia al guns anos. Também a partir de junho, Bruno Luiz Ribeiro da Silveira, que exerceu o cargo até novembro de 1976, quando foi substituído por M ário Brockman M achado, queno futuro Governo Sarney viria a ser Vice-Presidente, e Paulo Roberto Krahe, que ficou no cargo até abril de 1977, quando seafastou para assumir D iretoria no C N Pq, sendo substituído por Cid Sal gado deAlmeida, que havia trabalhado com Pelúcio no BNDE.

A 9 de outubro daquele ano, pelo $D$ ecreto $n-.76 .409$, foi determinado

"que as empresas públicas e sociedades de economia mista federais, bem como suassubsidiárias, quesejam usuáriasou adquirentes de bens de capital, organizarão, em caráter permanente, N úcleos deArticulação com a I ndústria ( N Al) com o encargo de promover, na compra deequipamentos, a preferência pelos de desenvolvimento e fabricação nacional" e criando "para afins de coordenação da atuação dos N A l a C omissão C oordenadora dos N úcleos de Articulação com a Indústria - CCN AI",

integrada por representantes do CD I, como Presidente, da C arteira deC omércio Exterior do Banco do Brasil S/A - CACEX, da M ecânica Brasileira S/A EM BRAM EC edaFIN EP, como Secretaria Executiva.

Esse papel foi ativamente desempenhado pela FINEP, formando e consolidando G rupos deTrabal ho com vistasà nacionalização e padronização de equipamentose componentes para viabilizar a produção interna em setores como os dematerial metro-ferroviário, instrumentação deprocesso, siderurgia eenergia elétrica. Ao final de1978, os N Al já somavam 113, contra apenas 88 em 1977. 7

\section{O sistema e os planos básicos}

0 Decreto №. 70.553, de 17 de maio de 1972, determinou que as atividades na área da Ciência eTecnologia fossem organizadas sob a forma de sistema, o Sistema N acional de D esenvolvimento Científico eTecnológico SN D C T. Embora o C N P q fosse designado Ó rgão C entral do Sistema, uma 
série de responsabilidades, especialmente nos aspectos econômico-financeiros, foram atribuídas ao M PC G . A letra do D ecreto, portanto, podia levar a conflitos decompetência. Pelúcio, já então Presidente da FIN EP, era desde1970, membro do Conselho D eliberativo do CN Pq, como representante do M PCG. As personalidadesdele, do Presidentedo CN Pq, G eneral Arthur M ascarenhasFaçanha, e do seu Vice-Presidente, M aurício M atos Peixoto, de quem Pelúcio havia anteriormente se tornado amigo, envidaram esforços para quetais conflitos não aflorassem ou tivessem repercussão abrandada. O sfinanciamentos que a FIN EP, como Secretaria Executiva do FN D CT, já vinha concedendo ao CN Pq e seus institutos, devem ter também contribuído para a superação de diferenças.

O I PBD CT foi aprovado pelo D ecreto no. 72.527 dejulho de 1973 para o período de 1973 - 1974. O II PBDCT, já com o CN Pq transformado em Conselho $\mathrm{N}$ acional de D esenvolvimento Científico eTecnológico, ${ }^{8}$ para o qual Pelúcio tinha sido nomeado Vice-Presidente, ${ }^{9}$ vinculado à Secretaria de Planejamento da Presidência da República, sucessora do M PCG , foi aprovado pelo D ecreto nํ. 77.355 de março de 1976.

Rappel, que coordenou as equipes responsáveis pelos planos, descreve como os fatos ocorreram:

“D esde o final dosanos 1960 que documentosgovernamentaisvinham fazendo referênciasa um plano deciência etecnologia o qual, no entanto, só veio a ter sua elaboração explicitada como meta da política no setor, em 1971, quando da edição do I Plano N aci onal de D esenvolvimento - PN D, relativo ao período 1972-74.

Elaborado em boa partepela equipedo N úcleo IV - Indústria, Ciência e Tecnologia, do M PCG, coordenado por Péúcio, o I PND, no capítulo sobre política cientifica e tecnológica, previa a montagem do PBD CT, ao lado de outrasmedidas relacionadascom o fortalecimento da infra-estrutura de ciência e tecnologia: a operação de um sistema financeiro para 0 desenvolvimento tecnológi co; o revigoramento da carrei ra de pesquisador; a implantação do sistema deinformação ci entifica etecnológi ca; a integração Indústria-U niversidade; a modernização das instituições de pesquisa e a reestruturação do CN Pq.

\footnotetext{
8 Lei n . 6.129, de 6 de novembro de 1974.

9 Decreto de 17 de fevereiro de 1975.
} 
0 propósi to do governo era promover a criação de um sistema nacional de ciência e tecnologia que proporcionasse os mei os para implantar e operar eficientemente uma economia industrial moderna e dinâmica. H averia, pois, que se estabelecer uma orientação para o desenvolvimento ci entífico e tecnológico, segundo uma perspectiva coerente com a evol ução da economia, a médio e longo prazos, com apoio de instrumentos institucionais, administrativosefinancei rosadequados, etraduzida em programase projetos com objetivos pertinentes e de conveniência assegurada. $D$ aí ter surgido a necessi dade de um plano de ciência e tecnologia que expressasse as intenções e realizações do governo, com o propósito de orientar a atividade da comunidadecientífica, buscando integrá-la ou, pelo menos, compati bilizála com o model o econômico adotado.

0 D ecreto de maio de 1972, que estabeleceu o SN D CT, atribuiu ao M PCG competência para preparar a proposta do PBDCT, em articulação com o CN P q eorganizou asaçõesna área de ciência etecnologia sob a forma de sistema, do qual deveriam fazer partetodas as unidades organizacionais de qualquer grau que utilizassem recursos governamentais para realizar atividades de planejamento, supervisão, coordenação, estímulo, execução ou controle de pesquisas científicas e tecnológi cas. A atuação integrada do sistema assim concebido seria objeto de um instrumento de previsão, orientação e coordenação, O PBD CT, queteria como esquema financei ro um orçamento - programa trienal, revisto e complementado a cada ano. 0 acompanhamento da execução dos programas, projetos e atividades decorrentes do PBDCT seria da responsabilidade do CN Pq. Assim é que, em meados de 1972, tiveram início ostrabalhos de elaboração do I PBD CT, centralizados na FIN EP, já então presidida por Pelúcio e que, desde junho de 1971, fora designada Secretaria Executiva FN DCT.

Logo deinício, a elaboração do PBD CT encontrou doisgrandesobstáculos. 0 primeiro devia-se ao fato de que 0 universo das organizações que compunham o recém-criado SN D CT era, então, pouco conhecido. N oâmbito da FI NEP e do CN Pq, o conhecimento estava limitado às institui ções que tradicionalmente exerciam atividades no setor, como o Instituto $\mathrm{N}$ acional de Tecnologia - IN T, o Instituto de Pesquisas Tecnológicas - IPT de São Paulo, e o Centro T écnico Aeroespacial - CTA, e àquelas cujos projetos de 
implantação vinham sendo apoiados financei ramente pelo FNDCT, a exemplo do Centro de Pesquisa e D esenvolvimento - CEPED da Bahia e Centro Tecnológico - CETEC de M inasGeraise dealgumasuniversidades quecriaram cursos dePós-G raduação. 0 segundo obstáculo era a exigüidade do tempo disponível para preparar a proposta do Plano, uma vez que a decisão de prepará-lo foi tomada com atraso de pelo menos um ano. $\mathrm{Ou}$ seja, no segundo semestre de 1972 havia que se preparar um plano de ação setorial para um governo que terminaria em 1974. Daí o I PBDCT ter nascido falho, isto é, apesar da legi slação estabelecer que o Plano teria um orçamento trienal, ol PBD CT abrangeu apenas o biênio 1973/1974.

A delimitação do universo a ser considerado para efeito do Plano foi fei ta através de coleta de dados einformações nosmini stérios, solicitando-se a cada um que preparasse a respectiva proposta setorial, consistindo de diretrizes políticas, metas, programas e projetos prioritários, atividades e orçamento.

A equipe responsável pela preparação do PBDCT, coordenada por Pelúcio, era constituída por três técnicos da FINEP em tempo integral e cinco consultores setoriais, em tempo parcial, especialmente convidados e cedidos pela comunidade acadêmica.

Inicialmente, a idéa da equipe era propor um plano de ação resultante da agregação e compati bilização dos efforçosque se programavam nosdiversos escalões setoriais do governo, consideradas as premi ssas básicas da política de desenvolvimento econômico definidasno PN D . Para tanto, precisava-sesaber o que se fazia, onde, quem, quanto se gastava e quem financiava.

Asinformaçõessobreproj etoseatividadesserviriam, pois, debasepara a devida interpretação das ações desenvolvidas no sistema de ciência e tecnologia. A partir daí se buscaria detectar as imprecisões, duplicações e falhas existentes, demodo a encami nhar correções eajustes necessári os à otimização do sistema, em função das metas políti cas estabeleci das pel o governo.

M as, durante a execução dos trabalhos, houve instruções diretas do M inistro para que a proposta do Plano se constituísse basicamente de uma listagem não exaustiva deprojetosprioritários, com indicação de objetivose entidades executoras, edeum orçamento global, com identificação dasfontes eusosdosrecursos. Assim, ol PBDCT passou a ser um plano meio desvirtuado, 
sem explicitação de estratégi as e diretrizes de políticas setoriais.

No final de um trabalhoso, difícil mas imaginoso processo de seleção de quais seriam os projetos prioritários e de alocações e cortes de recursos, chegou-se a uma proposta à qual posteriormente foi anexado um capítulo de política de ciência e tecnologia. Estava pronto o I PBDCT, que divulgar a ciência e a tecnologia como fatores fundamentais de desenvolvimento econômico e social do País.

O utro grande mérito do I PBDCT foi proporcionar amplo levantamento econhecimento do uni verso científico etecnológi co brasileiro, das ati vidades envolvidas, dos programas, projetos e atividades em curso e, ainda, de quanto sedespendia no setor. Passou-sea di spor de uma fotografia da realidade representada pelas atividades da comunidade de ciência e tecnologia, num dado momento. Caberia, então, ao governo a tarefa de procurar reorientar asdiversasações do sistema, demodo a eliminar ou, pelo menos, reduzir o estado de desorganização detectado.

Era o quese esperava queviessea ser fei to através do acompanhamento da execução do I PBDCT, ou quando da elaboração do II PBDCT. N 0 entanto, o acompanhamento limitou-se a uma coleta de informaçõessobreo desempenho dos projetos e atividades realizados em 1973. A mudança de governo federal no início de 1974, astranforormações por que passou o CN Pq, os trabalhos de preparação do II PND e, logo a seguir, do II PBDCT prejudicaram a análise e avaliação das informações coletadas, bem como provocaram a suspensão da atividade de acompanhamento.

A elaboração do II PBD CT, por sua vez, representava uma oportunidade desecorrigi rem asfalhasmetodológicaseasimprecisõesdo primé ro Plano. D epois de uma série de estudos envolvendo inclusive o exame de experiências similares em outros países e organizações (Plano da Índia; trabalhos da OCDE ${ }^{10} \mathrm{e}$ U NESCO ${ }^{11}$ ), procurando-se interpretar a metodologia mais adequada ao planejamento da ciência eda tecnologia no Brasil, sem necessi dadedesealterar a legi sação, propôs se ao novo governo que o PBDCT contivesse duas partes distintas, mas integradas. A primeira parte seria indicativa dos propósitos políticos do governo quanto ao setor, deforma a orientar as ações (programas,

\footnotetext{
${ }^{10}$ Organização para a Cooperação e o Desenvolvimento Econômico (Europa Ocidental, EUA, Canadá e Japão).

11 Organização das Nações Unidas para Educação, Ciência e Cultura.
} 
projetos e atividades) a serem desenvolvidas. Consistiria, pois, de uma declaração dosobjetivos, diretrizeseestratégiasda política dedesenvolvimento científico e tecnológico, das grandes prioridades e metas setoriais, dos programassetoriaisprioritárioseda estimativa global dosdispêndiosprevistos, abrangendo todo o qüinqüênio 1975/79. A outra parte detal haria as ações programadasno plano dosprojetoseatividades- em função das diretrizese metas identificadas na primeira parte - , abrangendo um período de três anos, er espectivo orçamento-progama.

A cada ano esta parte do PBDCT seria revista e ajustada, sendo acrescentadasas previ sões para maisum ano. Pretendia-se, com essemodel 0 metodológico, evitar que o PBDCT, ao ser aprovado mediante Decreto presidencial, setornasseum documento rígi do eetático, perdendo asprincipais características de um plano como instrumento de ação: flexibilidade e dinamismo. Ficaria portanto assegurada a possibilidade de se proceder à reorientação das ações do sistema, à medida que fossem detectadas falhase inadequações, através do acompanhamento do Plano. Com a mesma periodici dade se verificariam e divulgariam os resultados advindos de sua execução e das modificações e ajustes introduzidos, fossem a redi stribui ção ou concentração derecursosfinancei ros, a criação demecanismosinstitucionais ou as repercussões de um projeto sobre os demais.

M ontou-se um grande esquema de trabalho para a preparação do II PBD CT, sob a supervi são do C onsel ho Científico eTecnológi co do CN Pq, envolvendo grande parte dos pesqui sadores integrantes dos Comitês Assessores do C N Pq, além de vários técni cos da FI N EP. M ais uma vez, a coordenação dos trabalhos coubea Pelúcio, na qualidade de Presidenteda FIN EP eV ice-Presidente do CN Pq. Alguns ministérios, que já tinham seus sistemas setoriais de ciência e tecnologia estruturados, a exemplo do M inistério da Indústria e Comércio, da Saúde, das M inas e Energia, também tiveram uma participação importante na elaboração do II PBD CT. 0 interesse político eas expectati vas da comunidadeem participar da preparação do Plano eram muito grandes, em decorrência do impacto causado pela publi cação do I PBD CT. Entretanto, devido a uma série de razões de ordem tanto política quanto operacional, a metodologia de elaboração do II PBD CT seguiu basicamente osmoldes do anteri or, embora 
com uma inovação: antecedendo a listagem dos projetos e atividades de cada área, apresentou-se um esboço de política setorial, formulado a posteriori, expondo objetivos e metas, de forma a justificar a sel eção das prioridades.

A estrutura rígida do II PBDCT e a metodologia adotada na sua elaboração prejudicaram, da mesma forma como ocorreu com seu antecessor, a correção das di storções e falhas detectadas durante o acompanhamento, fossem denatureza quantitativa ou qualitativa, perdendo-sea oportunidade de se construir um instrumento de previsão, orientação, coordenação e avaliação da atuação integrada do sistema nacional deciência etecnologia."

\section{o grupo de pesquisa}

"Este Grupo, criado em 1972 na FIN EP em razão principal da incumbência do exercício da Secretaria Executiva do FN D CT", teve, "como finalidade principal, a realização de estudosque" orientassem "a aplicação dos recursos da Empresa e os do FNDCT, em novos programas na área de Ciência eTecnologia." 12

Fábio Stefano Erber, organizador e primeiro coordenador do Grupo, abordando o tema de uma perspectiva ampla, recentemente expressou-se sobre o que se passou:

"U ma dasfacetas do apoi o de Pelúcio àsativi dades de pesqui sa no País foi a instituci onal ização dessetipo deativi dadesno interior dasorganizações quedirigiu.

Sua preocupação com o tema estava baseada na percepção de que era importante para os aparel hos de Estado contarem com fontes próprias de informação e análise para melhor elaborar, monitorar e modificar as políticas públicas de que estavam encarregados. A contratação de outras institui ções, acadêmicas e de consultoria, não substituía o conhecimento decorrente da realização de pesquisas intra-muros.

Provavelmente, a longa experiência de Pelúcio no D epartamento Econômi co do BN DE, dedicado a estudos econômi cos setoriais e regi onais, 
foi importante para esta percepção. A forte presença no Rio de Janeiro de órgãos federais dedicados à pesquisa, como o IPEA e o IBGE, também vinculadosao M PCG, provavelmente reforçou sua orientação.

Da mesma forma, a vivência de Pelúcio no BNDE mostrou-lhe os problemas envolvidos na convivência, na mesma instituição, de departamentos operacionais e de pesquisa, cujos prazos e requisitos de informação são distintos. Pelúcio sempreteve presentequesubordinar a área de pesquisa às áreas operacionais significava transformar a primeira em assessoria da segunda, acabando por eliminar as atividades de pesquisa propriamenteditas. Esta segunda percepção levou-o a dar forma institucional específica às atividades de pesquisa intra-muros, a proteger essas atividades contra as demandaspor assessoria imediata advindas dasáreas operacionais e dar aos gestores da pesquisa o tempo e as condições necessárias para a realização deseustrabalhos.

Participei diretamente de duas iniciativas de Pelúcio visando institucionalizar atividades de pesquisas no âmbito do Estado: $0 \mathrm{G}$ rupo de Pesquisas da FINEP, do qual fui o organizador e Coordenador de 1971 a 1974, eo Instituto deEstudos de Política Científica eTecnológica do C N Pq, em 1978, que não vingou. As duas ini ciati vas são brevemente descritas a seguir. A partici pação de Pelúcio na criação do atual Instituto de E conomia da U FRJ merece mais destaque do que lhe dei no texto, mas detal há-la iria além do meu propósito, que se concentra nas pesquisas feitas intra-muros governamentais.

A primeira experiência que Pelúcio fez no sentido de estabelecer atividades de pesquisa orientadas para a política científica e tecnológica ocorreu em 1971, por intermédio da constituição deum G rupo de Pesqui sas - GPq no âmbito do M inistério do Planejamento, onde era Secretário Geral Adjunto. Por motivos administrativos (por exemplo, a contratação depessoal), esse G rupo foi transferido para a FIN EP em 1972, ondeexistiu até 1980.

Cabe notar que no início da década de setenta, os temas de política científica etecnológica não eram explorados pela comunidadeacadêmica. $\mathrm{N}$ a área governamental, o IPEA tinha recém-concluído três estudos pioner ros sobre a transferência de tecnologia eatividades dos institutos de 
pesquisa tecnológica, ${ }_{13}^{13}$ mas não manifestou interesse em dar continuidade a essa linha de trabalho. M esmo na área internacional, a literatura sobre esses temas ainda era incipiente.

O u seja, o G Pq veio a ocupar um campo em quea tradição de pesquisa no Brasil era muito limitada. ${ }^{14} \mathrm{~A}$ isto associou-se a juventude dos seus membros e sua limitada experiência acadêmica. ${ }^{15}$ Visto em retrospecto, Pelúcio era um "tomador de riscos".

Em sua primeira fase, de 1971 a 1974, o G Pq concentrou suasatividades em projetos que tinham forte proximidade com as prioridades da política econômica do período, como o desenvol vimento tecnológi co da indústria debens de capital e da indústria petroquímica ea demanda das empresas estatais por equipamentoseserviçostecnológi cos Composto por uma equipemultidisciplinar, em quehavia economistas, sociólogos e um engenheiro, desenvolveu métodos de pesquisa qualitativos apropriados a eses temas e inseriu-se na comunidade internacional, participando deprojetos depesquisa multinacionais.

Entre 1975 e 1978, sob a direção de José Tavares de Araújo J r. e, no fim do período, de M arcelo de Paiva Abreu, o G Pq abriu substancialmente o lequede pesquisas e recrutou diversospesquisadores seni ores, como L uciano M artins, M aria da Concei çãoTavareseSimon Schwartzman, querealizaram importantesprojetos sobrea burocracia brasileira, a organização da indústria nacional e a evolução da comunidade científica no País, além de dar continuidade aos estudos setoriais, a exemplo das indústrias farmacêutica e de alimentos.

A partir de 1979, 0 afastamento de Pelúcio da FIN EP coincidiu com a saída de váriostécni cossêni or do G Pq. Parte destes técni cosfoi, junto com Pelúcio, montar o programa de Pós-G raduação e Pesquisa da Faculdade de Economia da U FRJ, que, a seguir ganhou personalidade específica como 0 Instituto de Economia Industrial. ${ }^{16}$ Pelúcio teve importante participação neste processo, tendo sido o Vice-D iretor do Instituto, até afastar-se para dedicar-se à F undação L eonel Franca da PU C/RJ .

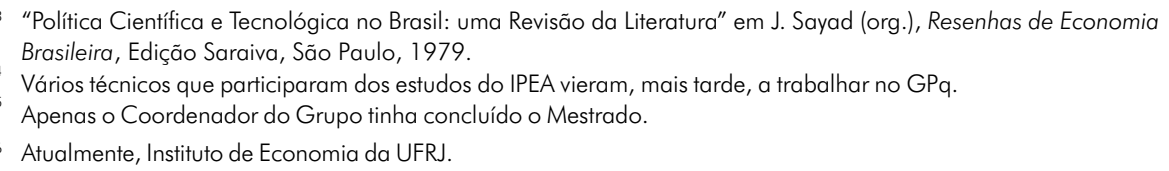


Em 1980, com a nova mudança na direção da FIN EP, o G Pq foi extinto.

Fogeaosmeus propósitosaqui avaliar plenamenteosresultadosobtidos pelo G Pq, mas cabe ressaltar que, entre eles, destacam-se: U ma robusta produção acadêmica; Legitimar eajudar a consolidação da área de pesquisa em ciência e tecnologia na academia; I mportantes contribuições para a política científica e tecnológica do País, como a concepção e avaliação de programas deapoi o; Formar quadrostécnicos, partedos quais sermaneceu na FINEP e outra parte foi trabalhar na academia e no setor público federal e estadual.

Em 1978, Pelúcio era Vice-Presidente do CN Pq, além de Presidente da FIN EP. A proximando-se o fim do G overno G ei sel, resolveu tentar uma institucionalização das atividades de pesquisa em política científica e tecnológi ca maisambiciosa, estabel ecendo um I nsti tuto com esse fim junto ao C N P q. U ma proposta de constitui ção do referido I nstituto foi elaborada por Candiota e por mim, sendo submetida ao Conselho. No entanto, dissensões internas impediram que fosse implementada antes do fim do G overno. A administração subseqüente do C N Pq abandonou a proposta. $\mathrm{N}$ a segunda metade dos anos oi tenta, a idéia foi retomada no M CT, mas teve curta duração."

Tavares de Araújo J r, que sucedeu a Erber na coordenação do G rupo, continua:

"Q uando o Pelúcio era Presidente da FIN EP, eu trabal hei no Grupo de Pesquisas- GPq de março de 1972 a dezembro de 1977, inicialmente como técnico e, a partir do final de 1974, como coordenador. Cheguei lá com 27 anos, recém-saído do M estrado da Fundação Getúlio Vargas, on de havia estudado por doisanos sob a orientação do M ário H enriqueSimonsen. Ao conhecer o Pelúcio, chamou-mea atenção um traço desua personalidade em comum com a de Simonsen: a mistura de argúcia e humor com que ambos expressavam seus pontos de vista.

$\mathrm{N}$ aquele momento, o GPq estava iniciando suas atividades sob a direção de Fábio Erber, e nosso primeiro projeto intitulava-se "Criação e Absorção deTecnol ogia na Indústria deBensdeCapital". A inexperiência da equipe formada por cinco membros: Fábio, eu, Sérgio Alves, que era engenheiro, e o único com al gum conhecimento prévio sobrea indústria de 
bens de capital; e duas estudantes de sociologia, Leonídia G omes dos Reis e M iriam Redinger, foi amplamente compensada pela clareza de Pelúcio quanto aos objetivos daquela pesquisa. A prendemos com elequea indústria debensdecapital constituía um dosfocosprioritários da política de ciência e tecnologia, porque nela seriam incorporados, em grande parte, os conhecimentos gerados na universidade e centros de pesquisa e que, posteriormente, seriam retransmitidos ao resto da economia sob a forma deinovações tecnológi cas. Portanto, aquela indústria continha a chave do dinamismo da economia e nós precisávamos descobrir os obstáculos que naquele momento estavam limitando o crescimento da produção de máquinasno Brasil.

$\mathrm{N}$ os meses seguintes, Sérgio Alves e eu visitamos os principais fabricantes de equipamentos do País, munidos de um longo questionário que apli cávamos aos dirigentes da empresa durante várias horas, além de passar o resto do dia percorrendo as instalações da empresa. M uitas vezes as entrevistas foram marcadas pelo próprio Pelúcio, quequeria estar seguro de que seríamos recebidos pelo presidente da empresa. Assim, tivemos a oportunidade de conhecer Cláudio Bardella, Einar Kok, Luís Eulálio Vidigal, Paulo Villares e vários outros. A cada duas ou três semanas, nos reuníamos na FINEP com Pelúcio, Alexandre e Erber para fazer um sumário das entrevistas realizadas no período. Em 1973, publicamos um pequeno livro descrevendo os resultados da pesquisa.

D urante seis anos, Pelúcio acompanhou de perto os trabalhos que fizemos no G Pq. D iscutíamos com ele os termos de referência de cada projeto, informávamos sobre o andamento e sempre aguardávamos a sua opinião antes de distribuir o relatório. Até meados dos anos 1970, nós éramos, talvez, o único grupo de economistas e cientistas sociais dedicados aos temas de ciência e tecnologia no Brasil. D iversidade, qualidade da equipe ecuriosi dade em relação ao que estava ocorrendo no resto do mundo foram três características que Pelúcio sempre buscou conferir ao G Pq. Aos trinta anos, eu coordenava uma equipe que contava, dentre outros, com Antônio Barros de Castro, G raça Sal gado, Eduardo Augusto Guimarães, Jacob Frenkel, J oséAlberto Reis, Leane N aidin, Luciano M artins, M aria da Conceição Tavares, M aria Fernanda Gadelha, M aria H elena Poppe de 
Figueiredo, M ario Possas, Luís0 távio Façanha, Ricardo Bielschowsky, Ricardo Tolipan, Sérgi o Abranches, Simon Schwartzman, SulamisD ain eVera M aria Pereira. No final de 1977, passei a supervisão do G Pq ao M arcelo de Paiva Abreu efui fazer um curso de D outorado na U niversidade de Londres"

\section{Formação de quadros dirigentes}

Em 1973, a SEPLAN fixou a estratégia de execução do Programa $\mathrm{N}$ acional deTreinamento de Executivos - PN TE, cuja criação representou 0 "reconhecimento, por parte do Governo Brasileiro, da importância da qualificação profissional, em nível gerencial com vistas ao esforço de modernização da empresa como um dos meios de acelerar o processo de desenvolvimento auto-sustentável do País" ${ }^{17}$

A FINEP iniciou sua participação na implementação do PNTE, financiando três cursos de M estrado em Administração: UFRJ/COPPE, Universidade Federal de M inas G erais - U FM G e Escola de Administração de Empresas de São Paulo da Fundação G etúlio Vargas - FGV.

O Instituto de Planejamento Econômico eSocial - IPEA haviainiciado em 1971, com o apoio do FNDCT, um programa com o objetivo de aumentar, em qualidade e quantidade, o número de planejadores e administradores para o desenvolvimento tecnológico pretendido para o País, desenvolvido na Universidade de Stanford, nos Estados U nidos. César Gonçalves N eto, da COPPE, e outros quatro, dois de São Paulo, um de $M$ inas $G$ eraise um do Rio $G$ rande do Sul, cursaram o M estrado, especialmente delineado naquela universidade e, em seguida, cada um fez um estágio de cerca de seis meses em instituições de pesquisas e desenvolvimento diferentes, regressando ao País em 1972.

"Em continuidadeao programa do I PEA evisando institucionalizar no Brasil a formação etreinamento de pessoal destinado a institutosdetecnol ogia em nível de gerente de pesquisas e desenvolvimento, procurou a FIN EP conhecer a experiência de outros paísesnessa área específica deformaçãa.

Contratou para esse fim, em final de 1972, os serviços da firma

17 Relatório de Atividades - FINEP - 1975. 
consultora Arthur D. Little do Brasil que, além desse trabalho indicativo, se propunha a adequar às condições brasileiras um programa com essa finalidade, desenvolven do inclusivecurrículo decursospara esse tre namento eformação especializada.

O strabalhosiniciados em 1973 abrangem trêsfases distintas:

a) levantamentos preliminares, em âmbito internacional e desenvolvimento de curricula alternativosadequados às condi çõesnacionais,

b) di scussão crítica com instituições nacionais, seus administradores e pesquisadores, visando a adequar um modelo curricular mínimo às finalidadesprocuradas;

c) Análise, alterações e adequações finais, destinadas a estabelecer 0 plano deimplementação do que seria o programa detreinamento eformação de gerentes em pesquisa e desenvolvimento." 18

N aquele mesmo ano, a FIN EP iniciou o Programa deTreinamento em Administração dePesquisas Científicas eTecnológicas- PROTAP, com o objetivo principal de complementar a formação profissional dos administradores do setor científico e tecnológico do País.

Tipicamente, o programa funcionava por módulos semanais, em regime deinternato, de modo a permitir que seus participantes pudessem se afastar de suasfunções por períodostoleráveis.

D os programas queali tiveram início eque se seguiram por muitosanos, participavam, em média, 25 técnicos de alto nível, pertencentes a instituições públicas eprivadas do País, enquanto queo corpo docentecontava com a presença deprofessores eespecialistasinternacionais.

Waldimir Pirró e Longo, que mais tarde, de 1984 a 1985, viria a ser Vice-Presidenteda FIN EP, participou da primeiraturma, assim descrevendo a experiência:

"Recebi uma carta dePelúcio convidando-mepara integrar a primeira turma do então criado PROTAP. Recebi-a como uma ordem, pois tinha a consciência de que eu e outros colegas, jovens pesquisadores, etávamos, por força dascircunsâncias, admi nistrando grandesgruposou mesmo instituições de pesquisa apoiados pelo FN D CT, sem experiência e sem um treinamento 
formal para gerenciar tais empreendimentos. Certamente Pelúcio havia percebido isto.

0 treinamento, conduzido pela consultora Arthur D. Little, foi realizado em três meses ao longo de um ano, em sistema de clausura em hotel situado em N ova Friburgo. Tal treinamento mudou totalmenteminha cultura epercepção acerca da ciência eda tecnol ogia, do seu papel no mundo moderno, sua relação com o poder nacional, suas consequêencias sociais e, também, sobre como organizar e gerenciar pesquisas e desenvolvimentos experimentais. Lembro-me ainda das aulas do inesquecível Jorge Sábato, da Argentina, do patriota e competente Kurt Politzer, de Sérgio Campos Trindade, JoséWalter Bautista Vidal e de diretores dos centros de pesquisa da Sony, da Phillips e da Arthur D. Little, D onald Schon.

Pelúcio com frequiência acompanhava osprofessores. N essas ocasõespude privar da sua companhia e ouvir suas opiniões, fazendo crescer em mim 0 respe to pela sua maneira de conduzir suas açõese palavras, sempre positivo e, de certa maneira, no estilo "Iow profile". Para mim, era um homem muito importante que se comportava como se ignorasse tal fato.

D ecerta maneira, o treinamento mexeu com a minha cabeça e mudou o rumo da minha carréra profissional. A partir dele, exercite osconhecimentos recebidos em diversas funções de chefia e meu interesse profissional ficou dividido entre a metalurgia e a política e getão de ciência e tecnologia. Paulatinamente, passe a publicar trabalhossobreo último assunto, comecei a ser requisitado como conferencista, como consultor, acabe dando aulasno PROTAP e, finalmente, em 1988, já na reserva do Exército e professor da Universidade Federal Fluminense - UFF, transferi-me do departamento de ciência dos materiais para o departamento de engenharia de produção, ondeleciono na graduação ena Pós-G raduação di sci plinasrelacionadascom política egetão de Ciência eTecnol ogia."

"D e1974 a 1978 foram trénados, nosdiversos ramosda administração de pesqui sas científicas etecnológi cas, cerca de 720 técni cos por intermédio de 64 semináriosereuniõesdetrabalho. Foram também concedidas 20 bolsasde etudo para especialização no exterior com vistasa criar um quadro deinstrutores para os cursosdo PROTAP, bem como para as universidades brasileiras N este quadriênio, mais de 90 técni cos de 15 países da América Latina edo Caribe 
participaram de eventos do Programa. Cerca de 36 instrutores e consultores etrange rosforam contratados para colaborar com o PROTAP" ${ }^{19}$

\section{Da pesquisa, ao desenvolvimento e até o produto}

D e1964 até1979, foram quinzeanosem quePelúcio esteve em posições de nítida importância nos assuntos de desenvolvimento científico etecnológico - fato raro na administração pública, não apenas no Brasil. Isto permitiu que seu trabalho pudesse ser apreciado em alguns casos, em todo o espectro convencional do assunto, isto é, desde a pesquisa, passando pelo desenvolvimento, atéa materialização do produto.

Ele, aliás, desde o início pretendeu que a FIN EP fosse capaz de dar seu apoio a projetos meritórios, cobrindo toda a sua amplitude, da concepção à realização. Isto foi conseguido plenamente como pode ser observado em casos concretos.

$M$ arcos $L$ uís dos $M$ ares- $G$ uia recordou recentemente um deles, que ele chamou de Efeito Pelúcio.

“N o inicio de1966, cerca de doisanosapóster eu retornado dosEstados U nidos com um doutoramento em bioquímica e estar ativamente engajado em pesquisa em enzimologia no D epartamento de Bioquímica, U FM G, numa manhã, entrou no meu laboratório um senhor de terno, bem vestido de óculos, que me disse: 'Sou do BNDE eestou visitando laboratórios onde há pesquisa para verificar como poderá o Banco vir a ajudá-loscom recursośs.

Levei-o a Carlos R. D iniz, Chefe do D epartamento de Bioquímica, e conversamos sobre as possibilidades. M eses depois, tínhamos em mãos um projeto aprovado, FU N TEC-66, que permitiu modernizar oslaboratórios inteiramente, em termos de equipamentos e materiais. I sso foi uma das bases do projeto de Pós-G raduação, que germinava naqueles dias, e que foi apresentado à Reitoria no ano seguinte.

Visitas por pessoal do BNDE, como essa, ocorreram em praticamente todos os centros universitários onde se realizava pesquisa com potencial de desenvolvimento tecnológico, o que criou uma alavancagem de qualidade

\footnotetext{
19 Relatório de Atividades - FINEP - 1978.
} 
em todo o País. A relação com o BN DE continuou nosanosseguintes, levando a um segundo projeto, FU N TEC-69, de maior amplitude.

A compreensão de Pelúcio de que não haveria possibilidade de real desenvolvimento tecnológico sem uma base científica forte era transparente nessas ações do BN DE, que continuaram nas da FIN EP.

Anosmaistarde, criamosa Bioquímica do Brasil S.A. - Biobrás, para o que muito contribuiu a modernização do D epartamento de Bioquímica da U FM G , ondea idéia da empresa germinou desde1968-1969. A Bi obrás iniciou operações de produção de enzi mas para as indústrias dealimentose farmacêutica em 1976 e, logo em seguida, vimosa oportunidade depesquisa e desenvol vimento na área de aproveitamento de resíduos celulósi cos para produção de etanol, com ênfase especial no bagaço de cana. E ram osanos do projeto do álcool combustível.

O rganizamos um projeto bem costurado e 0 apresentamos à FIN EP, com solicitação definanciamento. 0 projeto foi analisado e, um dia, recebemos um convite para reunião com o Presidente e diretores A posição tomada pela FIN EP nessa reunião foi um choque para a diretoria da Biobrás. Foinos proposto que a FIN EP entrasse como sócia no projeto, com recursos de risco, enão como financiadora apenas.

A leitura era simples: a FINEP concluíra que o projeto era muito importante, no mínimo como uma demonstração do que se poderia fazer, que o grupo tinha competência mas não tinha recursos suficientes, eque 0 apoi o com recursos de risco seria a forma de ter o projeto realizado.

N ão havia dúvida de quea visão clara e corajosa de Pelúcio era a base dessa decisão inovadora por parte da FIN EP.

0 projeto Bi oferm, como sechamava, foi montado. Construiu-seuma planta piloto, que entrou em operação em 1977-1978, e iniciou-se uma eletrizante ati vidade de pesquisa que culminou com o desenvolvimento de cepasautoprodutoras de celuloses A Bi oferm desenvolveu tecnologia na escala piloto para conversão de bagaço em etanol, com uso de celuloses e outras enzimasproduzi dasna sua planta-piloto. U ma análiseeconômica do projeto global feita anosmaistardeindicou sucesso técni co masinsucesso no retorno econômico, devido à alta demanda de energia e ao custo do bagaço, que se tornara quase uma commodity. 
A experiência da Bioferm foi a baseque permitiu à Biobrástrabalhar na produção de proteínas recombinantes, como a insulina humana, para cujo desenvolvimento tecnológi co muito contribuíram os financiamentos da FIN EP. A tecnologia foi desenvolvida e completada em um período de cerca de 8 anos, uma primeira patenteampla foi obtida nosEstadosU nidos em 1999 e, em 2000, a Biobrás recebeu o Prêmio FINEP de D esenvolvimento Tecnológico, por estes trabalhos e realizações. $\mathrm{H}$ oje, a empresa planeja uma fábrica de insulina recombinante, de porte para atender mercadossignificativos.

$N$ ão resta dúvida de quea inteligência privilegiada, a visão dealcance longo e a coragem de tomar deci sões complexas, características marcantes de Pelúcio, foram fatores impulsionadores de progresso no Brasil, demonstrados, neste caso, no micro-ambiente de uma empresa inovadora e que contou com essa inteligência entre seus apoiadores.

Creio que isso resume o que penso sobre o Efeito-Pelúcio no desenvolvimento da pesqui sa e Pós-G raduação no Brasil enosnegócios da Biobrás, que se fundamentaram em desenvolvimento tecnológi co próprio." O zires Silva, tendo presente que, desde 1966, isto é, três anos antes da criação da Embraer, o FU N TEC iniciou seu apoio ao CTA, do M inistério da Aeronáutica, por intermédio do Instituto Tecnológico da AeronáuticaITA e do Instituto de Pesquisa e D esenvolvimento - IPD, recentemente recordou outro caso:

"É com muito prazer, e cheio de reconhecimento, que volto atrás para relembrar os encontros - foram muitos - e discussões que tive com meu admirado amigo Pelúcio. Eu o conheci no final da década dos 1960 quando, do meu lado, lutava pelo desenvolvimento da construção aeronáutica no Brasil. Ele, estudioso e aplicado, esmerava-se em tentar produzir meios e processos para o Governo Federal estruturar e manter mecani smos de apoi o às pesqui sas ci entífi cas e tecnológi cas no País.

Essas discussões continuaram quando ele assumiu a Presidência da FIN EP em 1971. A marca do seu trabal ho criativo eemprendedor resiste até hoje, para alegria de seus amigos. Lembro-me de quando busquei 0 apoio da FIN EP em 1976, propondo a ele o projeto e o desenvolvimento do avião detrei namento militar - Tucano - quetanto sucesso na atualidade 
faz no mercado militar mundial. A Embraer estava dando seus primei ros passos e, na tentativa de atender futuras necessidades da Força Aérea Brasileira - FAB, pretendia desenvolver o Projeto. Como se sabe, 0 avião é uma máquina complexa. É sofisticada eamplamenteaborda tópicos do mais alto nível tecnológico. I sto resulta em dois problemas básicos, entre outros. $N$ ecessita de uma apreciável quantidade de diferentes especialistas e requer de 4 a 5 anos para gerar um novo produto. A FAB relutava em aceitar a idéia, pois considerava a experiência da Embraer insuficiente para desenvolver um avião de treinamento militar que apresentasse as qualidades operacionais e de vôo requeridas. Falei com o Pelúcio e, apesar de quebrarmos algumas regras de procedimentos da FINEP, pudemos assinar um acordo de financiamento que, embora pequeno, pois cobria apenas $10 \%$ do projeto, deu-nosa cobertura política. Em conseqüência, 0 Estado-M aior da FAB aceitou que, existindo um protótipo, faria sua avaliação técnica, dando-noso aval queprecisávamosjunto a outrasF orças Aéreas. 0 resultado foi de enorme sucesso. $\mathrm{H}$ oje, o Tucano, com mais de 600 aviões vendidos a 12 Forças Aéreas, inclusive da Grã-Bretanha e da França, deu origem à sua nova versão, o Super Tucano, com promissor sucesso, neste novo século. Assim era como agia nosso amigo Pelúcio, empreendedor e criativo, acreditando em pessoas e em idéias.

Fico contente em dar este testemunho sobre um grande brasileiro que, na sua brilhantetrajetória, soubecriar eapostar no futuro, oferecendo inúmeras oportunidadesa pessoas que, hoje ben eficiadas, sabem o quanto dele receberam."

\section{Linhas de atuação}

De modo simplificado, pode-se dizer que as linhas de atuação da FIN EP eram:

Apoio aU suários deServiços de Consultoria - AU SC, linhamestra desde a criação da Empresa, destinada a financiar a realização de estudos e projetos de desenvolvimento econômico esocial;

Apoio à C onsultoria N acional - ACN , atribuída à FIN EP em 1973 pela Portaria $n$-. 26, de 30 deabril do M PCG, destinada a financiar a implantação, 0 
desenvolvimento ea capacitação deempresas de consultoria, quando as existentes não podiam responder bem às demandas dos usuários da linha precedente;

Apoio ao D esenvolvimento Tecnológico daEmpresa N acional - ADTEN , destinado a financiar projetos de desenvolvimento tecnológico de interesse manifesto ou em potencial da empresanacional, cujacriação, pela sua importância e pioneirismo e também para que fosse possível se beneficiar de recursos do FN D CT, justificou aEM №. 252, de 31 deagosto de 1976, exposição demotivos específica que mereceu a aprovação do Presidenteda República.

FN D CT, destinado a financiar os programas e projetos prioritários de desenvolvimento científico e tecnológico compreendidos nos objetivos do Plano Básico de Desenvolvimento Científico e Tecnológico - PBDCT. 0 quadro abaixo mostra, no período indicado, o volume de financiamentos de cada uma dessas linhas.

Desembolsos Efetuados por Programa ${ }^{20}$ (R\$1.000,00 - Dez. 2000)

\begin{tabular}{|c|c|c|c|c|c|c|}
\hline \multirow{2}{*}{ Ano } & \multirow{2}{*}{ FNDCT } & \multicolumn{3}{|c|}{ FINEP } & \multirow{2}{*}{ Totais } & \multirow{2}{*}{$\begin{array}{l}\text { Totais } \\
\text { Gerais }\end{array}$} \\
\hline & & $\mathrm{ACN}$ & AUSC & ADTEN & & \\
\hline 1970 & 86.537 & & 10.325 & & 8.525 & 94862 \\
\hline 1071 & 139.399 & & $20.80 \%$ & & 20908 & 160.297 \\
\hline $\mid 0 / 2$ & 217602 & & 26.262 & & 26.262 & 243864 \\
\hline 1974 & $316.69 ?$ & 4.735 & 177.706 & 657 & 183.098 & 499.735 \\
\hline 1974 & 416.928 & 23.819 & t4k.947 & 6.891 & 179.657 & 196.585 \\
\hline 1975 & 439006 & $\$ 9.992$ & 250.G9 & 25.152 & 323.953 & 762909 \\
\hline 1976 & 434607 & 20.497 & $33 \times .713$ & 120514 & 479724 & 914.36t \\
\hline $19 \pi$ & $451.71 \mathrm{~B}$ & 21.622 & 129226 & 131.4111 & $2 \times 2288$ & 733.476 \\
\hline 1978 & 136.705 & 11,94 & 21454 & $1+5.2 \mathrm{k1}$ & 572.179 & 465.8B4 \\
\hline 1979 & 406.702 & $10.65 ?$ & 168.639 & 131654 & 310.451 & 717.635 \\
\hline Totais & $3,405,951$ & 143243 & 1.484 .369 & 559.563 & 2187.175 & 5,595106 \\
\hline
\end{tabular}

\footnotetext{
${ }^{20}$ Dados atualizados para dezembro de 2000, da Tabela IV, Capítulo 3, de "O Financiamento ao Desenvolvimento Científico e Tecnológico: Atuação da Financiadora de Estudos de Projetos - FINEP (1967-1987)" - Tese de Mestrado de Luís Martins de Melo, aprovada em Maio de 1988 - IEI/UFRJ.
} 
Especificamente sobre o fundo, em "Atuação do FN D CT no Período 1970/76", publicado pela FIN EP, estão relacionadas as operações aprovadas segundo os grandes setores do PBD CT e respectivos subsetores. No setor D esenvolvimento de N ovas Tecnologias, os subsetores Energia N uclear, Atividades Espaciais, Recursos do M ar eFontes e Formas não convencionais de Energia. No setor Tecnologia de Infra-estrutura, o subsetor Transportes. No setor Tecnologia Industrial, o subsetor Infra-estrutura e Projetos Específicos. No setor D esenvolvimento da Agropecuária, os subsetores Tecnologia Agropecuária, Recursos Florestais e Recursos Pesqueiros. N o setor Tecnologia Aplicada ao D esenvolvimento Regional e Social, os subsetores Programas Regionais Integrados, M eio Ambiente, Saúde, Alimentação e N utrição eTecnologia Educacional e o setor D esenvolvimento Tecnológico da Empresa $\mathrm{N}$ acional, além do setor $\mathrm{D}$ esenvolvimento Científico eFormação de Recursos $\mathrm{H}$ umanos.

Com relação a este último setor, é importante frisar que a FIN EP, como secretaria executiva do FN DCT, transferia recursos em volumes consideráveis para financiar programas do CN Pq, da CAPES e, a partir da transformação do BN DE deautarquia federal para empresa pública, também para o FU NTEC. A propósito deste, aliás, éindispensável notar que houve, no período 1970-1975, quando o FU N TEC foi extinto, umainformal, porém efetiva, divisão daclientela, basicamentea mesma, entreos doisfundos. Assim, paraquesetenhaum panorama mais abrangente do financiamento da Pós-G raduação naquele lustro, é imprescindível combinar as açõessimultâneas dos dois.

Ainda neste mesmo setor é relevante que se sublinhe quetran fferências foram feitas desde 1970 para a Academia B rasileira de Ciências - ABC, o que pôde dar impulso renovado àquela importante casa da ciência brasileira.

Transferênciastambém de porte considerável, ainda que, como as demais, sempre resultantes de análises de projetos, eram feitas para outros setores do PBDCT, tais como D esenvolvimento de Novas Tecnologias. No Subsetor Energia $\mathrm{N}$ uclear para aComissão $\mathrm{N}$ acional deEnergia $\mathrm{N}$ uclear - CN EN epara a N U CLEBRÁS, no Subsetor Atividades Espaciais, para o IN PE, então vinculado ao CN Pq, parao CTA do M inistério daAeronáutica, paraa D iretoria de Pesquisa e Ensino Técnico do Exército, epara as D iretorias de Ensino e de Administração do M inistério da M arinha, no Subsetor Recursos do M ar, para 
o Instituto de Pesquisas da M arinha - IPqM e para a D iretoria de H idrografia e $N$ avegação do $M$ inistério da M arinha. N o Subsetor Transportes, para órgãos dos M inistérios da Aeronáutica, dal ndústria e do Comércio, dosTransportese da M arinha, no Sub-setor: Infra-estrutura e Projetos Específicos, para órgãos do $M$ inistério da $M$ arinha, da Indústria e do Comércio, das $M$ inas e Energia, do Exército e para $G$ overnos Estaduais como os da Bahia, $M$ inas $G$ erais eR io $G$ rande do Sul e, ainda, para empresas estatais como a U siminas e D igibráse para empresas privadas como a Sociedade E ducacional Tupy.

Analogamente, transferências também eram feitas para os setores de Tecnologia de Infra-estrutura, Tecnologia Industrial, D esenvolvimento Tecnológico da Empresa Nacional, D esenvolvimento da Agropecuária e Tecnologia A plicada no D esenvolvimento Regional eSocial.

Em al guns desses setores, transferências derecursos do FN D CT também eram feitas para a própria FIN EP. É exemplo o Programa de Pesquisa H istórica eSócio-Econômica sobreo Papel da Ciência eTecnologia no D esenvolvimento $\mathrm{N}$ acional, criação e administração do já citado ADTEN , Fontes e Formas não Convencionais de Energia.

Por esses mecanismos, a FIN EP apoiou de forma vigorosa os I nstitutos de Pesquisa e D esenvolvimento dos G overnos Estaduais como o CEPED da Bahia e o CETEC de M inas Gerais e também os Institutos Setoriais do Governo Federal de diferentes Ministérios, como o INMETRO e a EM BRAPA, cabendo destacar, pelo volume de recursos envolvidos, o IM PA, do qual foi financiada a compra do terreno na Estrada $D$ ona $C$ astorina e pelo menos $70 \%$ do custo das edificações.

Também nas Ciências Sociais enas H umanidades a FIN EP foi atuante, notadamente a partir de 1975, quando foi autorizada pela E.M . 202, de 29 de julho, a instituir o Programa de Apoio à Cultura - Procultura, de que foram os primeiros beneficiários, com financiamentos substanciais, o Arquivo $\mathrm{N}$ acional eo Centro de Pesquisa e D ocumentação em H istória Contemporânea - CPDOC, da Fundação G etúlio Vargas. M ais tarde, outras instituições, entre elas o IU PERJ, a Casa de Rui Barbosa, o M useu do H omem da U FM G e a Fundação J oão Pinheiro foram apoiadas.

Anteriormenteao Procultura, havia sido financiada, em torno de 1974, a empresa de $M$ arcus Pereira, especialmente concebida para produzir discos 
de música brasileira que não interessavam às gravadoras estabelecidas. O s produtos obtidos incluíram um mapa da música regional brasileira e os discos "Flauta, Violão eC avaquinho" eainda músicas deErnesto N azareth, executadas por Arthur M oreira Lima. Foi também financiado o M useu da Imagem do Inconsciente, quetornou conhecido o grande trabalho de $\mathrm{N}$ ise da Silveira. 0 Projeto Portinari, quevisava organizar um catálogo completo e documentado da obra do grande pintor, foi financiado mais tarde.

\section{O personagem}

Pelúcio sempreconduziu aEmpresa desprovido de quaisquer preconceitos. As referências queele considerava eram apenas os objetivos a atingir, a qualidade do projeto e a capacitação dos que se propunham a conduzi-lo. $\mathrm{N}$ a sua longa gestão de nove anos à frente do FNDCT e da FINEP, foram financiadas instituições públicas e privadas, grandes e pequenas, civis e militares.

Longo, recentemente recordou-se de que conheceu

"José Pelúcio Ferreira em 1971, ao regressar ao Brasil, após conduir o D outorado na U niversidade da Flórida. No posto de major, havia eu recém assumido a chefia da Seção deEngenharia eC iência dosM ateriaisdo I nstituto M ilitar de Engenharia - IM E, ondehavia a idéia de se criar um Centro de Pesquisa em M ateriais - CPM , dotado de equipamentos modernos e pessoal qualificado que, paralelamente, além de trabal har em pesquisas de interesse do Exército e prestar serviços técnicos, funcionaria como suporte à PósGraduação. Todos os equi pamentos pertenceriam ao Centro que, em adição aos docentes, contaria com pessoal próprio inter ramente dedicado à pesquisa.

$\mathrm{N}$ a ocasião, a grandefontederecursospara a pesquisa ea Pós G raduação era o Fundo $\mathrm{N}$ acional de $\mathrm{D}$ esenvolvimento Científico e Tecnológico FNDCT, que já vinha apoiando, decididamente, a implantação dos programas de M estrado e de D outorado no IM E. Assim, elaborou-se um projeto para solicitar recursos do FNDCT, tendo eu sido indicado para entregá-lo, pessoalmente, ao presidente da FIN EP.

$M$ arcada a audiência, lá fui eu, devidamentefardado, para a avenida Rio Branco, $124-13^{\circ}$ andar. D epois de pouca espera, entrei preocupado no gabinete do, já famoso para mim, Pelúcio. E aí, uma surpresa! Ao invés de 
encontrar um tipo impressionante detecnocrata federal, frio, superior, senhor do seu poder e, seguramente, de fala solta earrogante, tinha diante de mim exatamenteo oposto! U m cidadão depequena estatura, sério, dejei to tímido, a olhar para mim, em pé, por detrás degrossas lentes dos seus óculos. Era de pouco falar. Após sentarmos, ouviu minha argumentação, pacientemente, com o ol har demonstrando simpatia e muito interesse. A reunião durou pouco. Ele mandou protocolar o projeto e despediu-se dizendo que eu aguardasse uma resposta. $N$ ão acenou com um sim, nem com um não. Saí realmente impressionado com aquele cidadão tão afável. Esse, então, era o importante Pelúcio? Confesso que havia gostado dele.

0 projeto do CPM foi aprovado, assim como tantos outros do IM E, mudando, em conseqüência, significativamentea trajetória do Instituto e daqueles que lá labutavam, esperan çosos de di sporem de mei os adequados para contribuírem para o desenvolvimento nacional e para a plena realização profissional."

Como regra, cada M inistério Civil tinha a sua D ivisão de Segurança e Informação - DSI e seu chefe, normalmente, um O ficial-G eneral da reserva, quase sempre do exército, respondia, na hierarquia, ao M inistro da pasta, mas se relacionava também diretamente ao Serviço N acional del nformações- SN I, cujo titular era M inistro de Estado.

As organizações da administração indireta, autarquias, fundações e empresastinham, cada uma, a sua Assessoria de Segurança el nformação - ASI, onde o esquema se reproduzia. 0 C hefe de Assessoria respondia, na hierarquia, ao titular da organização, porém relacionava-se diretamente com o Chefe da DSI do M inistério. 0 arranjo permitia que os ministros e os titulares das respectivas organizações vinculadas, se desejassem, ficassem livres dos problemas queviessem a aparecer nos assuntos de segurança. C aso fosse vedada a participação de um pesquisador num congresso no exterior, ou impedida uma contratação, ou até uma demissão fosse recomendada, ele, se quisesse, sempre poderia dizer que eram assuntos que escapavam à sua área de competência.

Só recentementevim a saber, por intermédio deAlexandreeC lélia, porque a FIN EP nunca teveASI. Pelúcio havia proposto à autoridade competente, que a elemesmo, o Presidente, fossem atribuídas todas as responsabilidades naqueles assuntos. E conseguira argumentos convincentes para obter concordância. 
A FIN EP, quando julgava que os projetos apresentados tinham mérito, financiava-0s, independentemente da simpatia quea I nstituição pudesse gozar, ou não, do regime. Tal foi o caso, para citar um exemplo, dos projetos do Centro Brasileiro de Análises e Planejamento - CEBRAP. E quando, para compor suas equipes, verificava que determinado talento estava disponível, após as considerações, pelas quais Pelúcio tinha deassumir responsabilidade plena, 0 indivíduo era contratado. D o depoimento de M aria da Conceição Tavares, publicado em 1987 no opúsculo "FINEP - Vinte Anos", reproduzo:

"M inha vinda para a FIN EP se deu num momento muito difícil: 0 do fechamento político no regime autoritário, entre 1971 e 77, quando a insti tui ção desempenhou um papel muito importante. Com asuniversidades carentes deapoi o político, a FIN EP não selimitou ao auxílio institucional. C riou, dentro da própria casa, grupos de pesquisa quedavam suporteàssuas atividades básicas de promoção da tecnologia e realizavam trabalhos. $A$ FIN EP foi o órgão do governo que, por sua isenção e pela vi são de estadi ita de seu presidente, José Pelúcio Ferreira, apoiou pesquisas na área social, permitindo que um grupo de cientistas do setor, mal visto pelo regime inclusive penalizado - trabalhasseem projetos decrítica à própria natureza do Estado brasileiro".

E Simon Schwartzman, conclui:

"Trabalhei com Pelúcio no final dos anos 1970, sociólogo no meio de tecnólogos, engenhei ros, economistase admi nistradores, ajudando a abrir as áreas de cultura e ciências sociais da FINEP, e desenvolvendo um amplo estudo sobrea história social dasciênciasno Brasil. $\mathrm{N}$ em todosentendiam 0 que eu fazia (talvez nem eu mesmo), mas o apoio e a confiança de Pelúcio era uma referência firmee constante, ecom isto todasasidéiasepossi bilidades poderiam ser testadas e experimentadas.

Lembro dePelúcio como minei ro queera, não só defato, mas sobretudo dealma. D o mel hor de M inas havia herdado as convi cções nacionalistas, a crença de que o Brasil precisava desenvolver suas próprias competências e fazer o melhor uso de seus recursos. D o melhor de M inas havia herdado também o espírito dehomem público, a dedi cação à causa que o empol gara, a do desenvolvimento da ciência eda tecnol ogi a nacionais. Estas convicções, no entanto, não faziam dele um homem formal, rígido, e muito menos 
autoritário. Q uem entrassena sala da Presidência da FIN EP naquelesanos encontraria sempre uma conversa descontraída, sem fim, cheia de casos e anedotas, com muito humor e muito riso. O s participantes, quase sempre, eram cientistas, empresários, homens de governo, técni cos da própria FINEP. Pela informalidade era como Pelúcio conhecia as pessoas, criava vínculos pessoais e decidia em quem confiava e com quem gostaria de trabalhar. Como quem não quer nada, asinformaçõesfluíam, os juízos eram formados, as deci sões tomadas.

A informalidadeno estilo estava associada a uma preocupação absoluta com os resultados eum total desinteresse pelasformali dades easburocracias. As decisões eram feitas ouvindo quem mais entendesse de cada tema, os recursoseram entreguesa quem tinha capaci dadedeagi $r$ emostrar resultados earranjosinstitucionais efinance ros eram inventadosereinventadosa cada momento, conformeo que fossemai sútil eeficiente. $\mathrm{H}$ avia um clima euma sensação de que nada era impossível, sempre haveria recursos e formas de levar à frente projetos e idéias novas e promissoras.

Pelúcio não se afastava de seus valores e princípios, mas não era um ideólogo. Buscava a competência ea inteligência ondeestivessem, entre civis emilitares, conservadorese esquerdistas, homenspúblicose empresários. Ele parecia conhecer todo mundo, descrevia em detalheprojetosem áreastécnicas complicadas e tinha amigos em todos os círculos. Esta abertura de espírito e falta de sectarismo permitia que ele convivesse e fosse bem aceito em todas partes, econsegui ssefazer da FIN EP uma instituição queespal hava esperança em temposainda tão difícés do regime militar brasileiro.

Para quem conviveu com Pelúcio naquelesanos, e conheceu a FIN EP queelehavia criado, foi uma experiência euma lição devida extraordinárias."

\section{O resultado}

Pelúcio demonstrou extraordinária competência e habilidadeem reunir talentos de origem variada, não apenas de formação tecnológica e das ciências naturais, porém, trazendo também a inserção das ciências sociais e humanas, à época, freqüentemente, menos consideradas nos chamados meios científicos. 0 resultado foi esplêndido. 
Ao final de sua administração, Pelúcio deixou para seus sucessores uma Empresa com ampla cobertura nacional. Além do pequeno escritório que a FIN EP havia estabelecido em São Paulo, gerenciado por G erson Edson Ferreira Filho, que viria a ser Presidente da Empresa de 1980 a 1983, dispunha, como agentes financeiros para o AU SC, do Banco da Amazônia, Banco do N ordeste do Brasil, Banco Regional de D esenvolvimento do Extremo-Sul, Bancos dos Estados de Pernambuco eAlagoas e Bancos de D esenvolvimento dos Estados do M aranhão, Rio G rande do N orte, Bahia, Espírito Santo, M inas G erais, Rio de Janeiro, São Paulo, Paraná, e Goiás; e para o ADTEN, do Banco Regional de Desenvolvimento do Extremo-Sul, Banco do Estado de Pernambuco e Bancos de D esenvolvimento dos Estados da Bahia, de M inas Gerais, do Paraná, e deSão Paulo. D ispunha também detrêsAgentesT écnicos: o C entro T écnico Aeroespacial, o Centro deEstudosTecnológicos de M inas Gerais e o Instituto de Pesquisas Tecnológicas de São Paulo, para análise e fomento de projetos e programas em suas respectivas áreas e para consultoria especializada em projetos específicos. $\mathrm{N}$ a Bahia, o Centro de Pesquisa e D esenvolvimento havia firmado convênio de assistência técnica com o Banco de $\mathrm{D}$ esenvolvimento do Estado da Bahia, quando do credenciamento deste como agentefinanceiro do ADTEN .

A empresa estava habilitada a apoiar todos os estágios da pesquisa, desde a fundamental, passando pela aplicada, chegando ao desenvolvimento experimental e, indo mais além, para cobrir também o financiamento de protótipos enovos produtose processos, quando necessários, precedidos pelos pertinentes estudos de viabilidade. Ela financiava, no que tange a áreas do conhecimento, as ciências da natureza, as engenharias, as ciências da saúde, a agricultura e as ciências sociais e humanas.

Para tal , a Empresa manejava ampla variedade de instrumentos, desdeo financiamento não reembolsável ou com jurossubsidiados atéo crédito comum, chegando à participação acionária em empresas de alta densidade tecnológica. N este caso, à época, estavam sete empresas, a saber: Tectronic S/A - Empresa Brasileira deTecnologia Eletrônica, Sulfab - Companhia Sulfo Q uímica da Bahia, Bioferm - Pesquisa eD esenvolvimento $S / A$, D igibrás - Empresa D igital BrasileiraS/A, M icrolab S/A, C emag - C eará M áquinasAgrícolas S/A ePropar - Promoções e Participações da Bahia S/A. 
Em fevereiro de 1979, naApresentação do Relatório deAtividades de 1978, o último que ele assinou como Presidenteda FIN EP, Pelúcio disse:

"D urante mais de onze anos, a FINEP veio acumulando apreciável experiência no trato de questões que abrangem desde o financiamento de pré invesimento, com queiniciou suasatividades, atéresponsabilidades maiorese mais complexas, assumidas com o apoio à pesquisa científica etecnológica em U niversidades Insitutose Empresas $\mathrm{N}$ acionais, tanto públicasquanto privadas Ao término desseperíodo consolidou-sea FIN EP como autênticoBanco N acional de D esenvolvimento Científico eTecnológico.

D exjo registrar o meu reconhecimento ao corpo defuncionários da Empresa ea todos os que, direta ou indiretamente, contribuíram para a obtenção desse resultado. M emo reconhecendo o muito que resta por ser fáto, éinegável que o saldo positivo das realizaçoes inovadoras da FIN EP já Ihe atribuiu lugar de destaqueentre as Instituiçōes voltadas para o desenvolvimento de nosso País eo bem-etar desua população." 
